\title{
Research on Construction of Academic Quality System for Students of Adult Higher Education
}

\author{
Xiaorong Gan \\ Department of Psychology \\ Gannan Medical University \\ Ganzhou, China 341000
}

\author{
Wen $\mathrm{Hu}$ \\ Department of Psychology \\ Gannan Medical University \\ Ganzhou, China 341000
}

\begin{abstract}
Documentary method is used to summarize theories on evaluation of students' academic quality in adult higher education. Existing problems of students' academic quality in adult higher education are explored through interviewing method. Besides, the advanced experience of western countries in construction of academic quality system is analyzed, in order to propose countermeasures to build the system of our country.
\end{abstract}

Keywords-adult education; academic quality; system construction

\section{INTRODUCTION}

\section{A. Adult Higher Education}

Adult higher education bases on secondary education, referring to a high professional education with rich contents and forms for the service of social development. It is the extension and supplement of regular higher education. It makes the traditional closed higher education become open and provides the opportunities for more adults to receive higher education; meanwhile, it contributes to more diversified and richer layers, types, specifications, objectives and forms of higher education [1]. With the soaring economic development of our country, the society has increasingly high requirements for laborers. An increasing number of people receive higher education. Therefore, it is necessary to pay close attention to social demands and the development of adult higher education.

\section{B. Academic Quality Evaluation}

The evaluation of students' academic quality is a problem that attracts the attention of colleges. In foreign countries, it first happened in the 1930s. Students' academic quality is evaluated through testing their knowledge and memory [2]. In the 1950s, Taylor's theory of "Target Center Model" is widely-used in educational circles. It compares students' final academic results with the prescribed educational objectives to evaluate students' academic quality and emphasizes the dominant position of test and examination [3]. In the 1970s, students' learning process is evaluated. Bruner mode and CPIP mode appear, paying more attention to training students' emotion and operating skills [4]. After the 1970s, under the influence of "pluralism" value, valuators and students can carry out equal dialogue, mutual consent and participation in the evaluation of students' academic quality. It embodies the diversified evaluation subjects and criterions.

The evaluation system of students' academic quality can reflect whether the education reach the prescribed goals. However, according to the research on literature, most scholars of our country attach importance to basic education and regular higher education instead of adult higher education. Therefore, it has crucial theoretical significance to build the evaluation system of students' academic quality in adult education through referring to advanced experience of western countries on the basis of current situation of students' academic quality evaluation. At the meantime, teachers can effectively know about their teaching quality and methods according to the evaluation results, in order to improve their teaching, adjust teaching plan and accumulate more teaching experience, furthest improve the teaching effectiveness.

\section{EXISTING PROBLEMS OF EVALUATION ON ST UDENT S' ACADEMIC QUALITY IN ADULT HIGHER EDUCATION}

According to investigation and interview of department head and students of adult education college of Gannan Medical University as well as literature review of students' academic quality evaluation of adult higher education, the characteristics of students' academic quality evaluation in adult higher education of our country are as follows:

\section{A. The Evaluation Contents Lack Pertinence.}

Students of adult education come from various places and have diversified identity and knowledge background. The evaluation system of their academic quality should be flexible instead of sticking to one pattern. However, the existing evaluation system pays attention to the assessment of theoretical knowledge instead of practical quality of students to find, analyze and solve problems. The evaluation contents are more one-sided than scientific.

According to the survey, teachers use similar methods for students in adult education and regular education. They teach theoretical knowledge in class and fail to know about students' life and social and working background and train students' practical ability. It violates students' strong desire in applying their knowledge and influences the effect of adult learning. 


\section{B. The Evaluation Subject Lacks Flexibility}

The Temporary Provision of Evaluation on Colleges stipulates, "The evaluation on education in colleges is an important form to supervise colleges and implemented by the people's governments at all levels and administrative departments for education". The evaluation on students in colleges is implemented by departments in charge of teaching. Students as learning subjects are in passive position. Students of adult education are no exception.

\section{The Evaluation Methods Are Not Scientific}

According to the investigation, adult education colleges or schools of continuing education have no full-time teachers but invite teachers of regular higher education to teach. The organizational form of teaching and the employment of teachers go against the teaching for students in adult education. Many teachers are not familiar with characteristics of students in adult education. Therefore, they fail to pay attention to teaching key points.

\section{Little Importance Is Attached to the Evaluation Process}

The management system of students' academic quality in adult education fails to use modernized evaluation and management means. Teachers evaluate randomly with strong subjectivity. The results are not objective, scientific and accurate. So it has low reliability and validity. At present, the evaluation on students' academic quality in adult higher education faces problems about how to organically comb ine qualitative evaluation with quantitative evaluation and transform the evaluation pattern with few monitoring of the process.

\section{E. The Evaluation Concept Lacks Humanistic Care}

Students investigated are diffident in learning ability, academic record and pursuit of diplo ma as well as future work. Furthermore, teachers and instructors of adult education fail to pay attention to it and give corresponding psychological guidance. The evaluation on students' academic quality of adult education seldom pays attention to students' outlook on life, world outlook and psychological quality.

\section{ADVANCED EXPERIENCE OF WESTERN COUNT RIES}

\section{A. Make The Evaluation More Pertinent}

According to the existing quality evaluation system of American higher education, "State governments have minimum standard for conditions of school operation for colleges to grant permission for them; intermediary organ is one of the subjects of evaluation. No absolute approval standards are provided for its identification. Leading requirements exist for theory on school management, teaching, scientific research and service of colleges. The auditing pattern of colleges in Britain fully respects colleges' autonomous right in quality. Colleges set quality goals to carry out quality management. The Quality Assurance Agency evaluates the effectiveness of it." [5]

In adult higher education, our country should implement national or regional quality evaluation through auditing and identification according to learning characteristics of adults and practical situation of majors. Therefore, the construction of evaluation system for students' academic quality should base on different majors and characteristics of students.

\section{B. Further Clarify the Responsibility of Evaluation \\ Management and Implementation and Construct the System for Evaluation of Intermediary Organs}

According to some scholars' research, "In quality certification system of American higher education, the US Department of Education and nongovernmental certification committee do not directly approve but accept certification authorities and play the function of supervision, restriction and coordination. Certification authorities approved are the executive body to approve colleges. The Quality Assurance Agency is the executing agency to audit colleges and has autonomous right in employment, income and expenses of expenditure and internal management. Higher Education Funding Council manages the evaluation of the Quality Assurance Agency through supervision and auditing."

Referring to the experience, the government of our country should highlight the function of macro-direction and standard supervision, train, guide and evaluate intermediary organs and make professional society of higher education evaluation and intermed iary organ come into play.

\section{Pay Attention to Rate of Resource Utilization and Students' Learning Effectiveness}

In recent years, the indicator system of quality evaluation in higher education pays more attention to learning outcomes. For example, there are two indicators (acquisition, discovery and application of knowledge, learning and effective teaching of first grade students in five first grade indexes newly issued in 2003 by A merican North Central Certification Institute [6]. After canceling the direct teaching quality evaluation of colleges, the Quality Assurance Agency issues new standard for degree awarding that states the learning effectiveness degree gainers should reach in detail.

The adult higher education of our country should conform to the characteristics and tendency of quality evaluation in international higher education and guide colleges to construct unique evaluation system of students' academic quality. They should pay attention to learning effects as well as learning process, train students' learning ability and the formation of humanistic quality.

\section{THE STRATEGIESTO CONST RUCT EVALUATION SYSTEM FOR ST UDENT S' ACADEMIC QUALITY IN ADULT HIGHER EDUCATION OF OUR COUNTRY}

The adult learning evaluation in our country pays attention to summative assessment, knowledge examination, teachers' evaluation and academic record instead of process assessment, practical application, students' self-assessment and training of humanistic quality. At present, a diversified evaluation system for adult learning with diversified evaluation methods and contents and subjects as well as scientific evaluation process that centers on competence ass es sment should be constructed. 


\section{A. Use Diversified Evaluation Methods}

According to the research and development of evaluation system for adult education, examination is the only way to evaluate students' academic quality in adult education. Diversified student-oriented evaluation methods should be adopted to meet the requirements of quality-oriented education. For example, the test of comprehensive ability of knowledge should let students practice and submit report. The test of language competence should be carried out through integration of oral test, listening test and written test. "Integrate methods like written test, oral test, demonstration and intelligence test with qualitative and quantitative analysis, apply debate, lecture, competition, course design, thesis, class report, stage performance and demonstration to supplement open-book and closed-book examinations, in order to guarantee the quantity and the quality of evaluation.

\section{B. Formulate Diversified Evaluation Targets}

Students of adult education have diversified experience in family life, work unit and school life. As independent individuals, they are integration of moral cognition, moral emotion, moral will and moral behavior. Therefore, diversified evaluation targets should be formulated to make adult students acquire knowledge and improve practical ability and realize the integrated development of them.

\section{Form Systematic Evaluation System}

Learning is progressive and has different objectives in different stages. Therefore, the construction of evaluation system should pay attention to the development of students' learning. Before teaching, teachers should know about the level of each student through diagnostic evaluation; in teaching, they can know about students' acquisition of knowledge through investigation of learning situation and evaluation of learning quality; after class, they should evaluate whether students reach the prescribed teaching objectives through summative evaluation.

\section{CONCLUSION}

To sum up, the evaluation system on students' academic quality in adult higher education has many problems. It is necessary to construct a diversified evaluation system with diversified evaluation methods, contents and subjects as well as scientific evaluation process that centers on competence assessment for adults' learning on the bas is of absorbing advanced experience from western countries, in order to promote the development of adult higher education in our country.

\section{REFERENCES}

[1] Song Jing. Research on Variation of Adult Higher Education of Our Country under the Background of Credential Society, Master's thesis of Suzhou University

[2] Education Policy Analysis, OECD, 1998

[3] Werner Mauch. World Trends in Adult Education Research. UNESCO Institute for Education. 1999

[4] Oser, F. K, Dick, A, Effective and Responsible Teaching. The new synthesis, Jossey Bass Publisher, San Francisco, 1992
[5] Du Wei. Research on Evaluation System of Students' Academic Quality in Adult Higher Education, master's thesis of Southwest University

[6] Zhan Xiuzhen. Exploration on Teaching Quality Assurance System of Adult Higher Education [J], Continue Education Research, 2009(9), P147-148

[7] Cui Ruifeng, Tian Dongping. Self-evaluation of Institutions of Adult Higher Education in America: Connotation, Examples and Characteristics, [J], Modern Distance Education, 2008(1) 